\title{
Nonlinear Model of Pseudoelastic Shape Memory Alloy Damper Considering Residual Martensite Strain Effect
}

\author{
Y. M. Parulekar and G. R. Reddy \\ Reactor Safety Division, Bhabha Atomic Research Centre, Mumbai 400085, India \\ Correspondence should be addressed to Y. M. Parulekar, yogitap@barc.gov.in \\ Received 15 August 2011; Accepted 30 October 2011 \\ Academic Editor: Mohammad Tawfik
}

Copyright ( $) 2012$ Y. M. Parulekar and G. R. Reddy. This is an open access article distributed under the Creative Commons Attribution License, which permits unrestricted use, distribution, and reproduction in any medium, provided the original work is properly cited.

\begin{abstract}
Recently, there has been increasing interest in using superelastic shape memory alloys for applications in seismic resistant-design. Shape memory alloys (SMAs) have a unique property by which they can recover their original shape after experiencing large strains up to $8 \%$ either by heating (shape memory effect) or removing stress (pseudoelastic effect). Many simplified shape memory alloy models are suggested in the past literature for capturing the pseudoelastic response of SMAs in passive vibration control of structures. Most of these models do not consider the cyclic effects of SMA's and resulting residual martensite deformation. Therefore, a suitable constitutive model of shape memory alloy damper which represents the nonlinear hysterical dynamic system appropriately is essential. In this paper a multilinear hysteretic model incorporating residual martensite strain effect of pseudoelastic shape memory alloy damper is developed and experimentally validated using SMA wire, based damper device. A sensitivity analysis is done using the proposed model along with three other simplified SMA models. The models are implemented on a steel frame representing an SDOF system and the comparison of seismic response of structure with all the models is made in the numerical study.
\end{abstract}

\section{Introduction}

Shape memory alloys (Ni-Ti alloys) are unique alloys that have the ability to undergo large deformations but can return to their undeformed shape by heating (shape memory effect) or through removal of the stress (super elastic effect). Recently, there has been increasing trend in using super elastic shape memory alloy devices based on wires for applications in structural vibration control.

The significant properties of SMAs like Pseudoelasticity, large ductility, excellent corrosion, and fatigue resistance make these alloys attractive material for structural vibration control. Graessar and Cozzarelli [1] in 1991 first proposed the use of Nitinol (SMA) as damping materials. They studied the effect of loading frequency and history on the energy dissipation characteristics of SMA wires. They also proposed a one-dimensional constitutive model for pseudoelastic behavior of the model. The study on the use of SMAs for passive structural damping is presented in Thomson et al. [2] in 1995, where three different quasistatic models of hysterisis were reviewed and compared with experimental investigation of a cantilever beam restrained by two SMA wires. Later, Clark et al. [3] and Dolce et al. [4] in 2000 demonstrated the feasibility of the concept of SMA wire device conducting large number of experiments. It is observed from the tests conducted that there exist the residual martensite strain effects in the hysterisis loop of the SMA device. This effect increases the hysterisis energy dissipated and thus further helps in the control of seismic response. Dolce et al. [5] also studied the implementation of various configurations of SMA-based special dampers by shaking table tests on RC structures. Researchers also have done representative works in thermomechanical modeling like Tanaka [6], Liang and Rogers [7], Boyd and Lagoudas [8]. Based on their work, Khan et al. [9] developed simplified hysterical model of device based on SMA tubes. Motahari and Ghassemieh [10] proposed a simple multilinear model and proved it to be accurate. However, all these models do not take into account the residual martensite strain accumulation effects due to cyclic loading during earthquake. Experimental studies by 
Lexcellent and Bourbon [11] and Miyazaki et al. [12] have shown that SMAs change in their mechanical cyclic behavior when subjected to cyclic loading and there is $20 \%$ reduction in transformation stress. They also observed that there is accumulation of residual strain for austenitic $\mathrm{Ni}$-Ti wires with number of cycles under repeated cyclic loads which attains a value of $0.4-0.5 \%$ at room temperature after about 50 cycles. In the past, most of the works simply neglected this residual strain in the model of SMA damper subjected to earthquake loads. Thus, in the present paper, the model proposed in [10] is modified to include the effect of residual martensite strains. Work presented by Andrawes and DesRosches [13] shows that the response of SMA model is more sensitive to cyclic effects in case of earthquakes with long duration or large intensities. Parulekar et al. [14] modified an existing thermomechanical [10] to incorporate the residual martensite deformation observed in austenitic SMA wires and thus take into account the cyclic effects of SMAs. However, in order to accurately represent the dynamic experimental hysterical loop of pseudoelastic SMA wire device, the thermomechanical model is further modified in this paper considering the decrease of apparent modulus of elasticity of the austenite while unloading. The computationally efficient physically based proposed model quantifies the effect of pseudo-elasticity on wide range of system parameters like SMA operating temperature, hysterisis, structural stiffness, hardening, softening, displacement due to phase transformations, residual martensite strains, and reduction of modulus of austenite during unloading. Although many other simplified models are available in the literature, this model gives accurate prediction of the experimental response in view of modeling the residual strains. The modified multilinear model of SMA device also predicts the experiment precisely. Comparison of different simplified SMA models is made with the proposed model using an application of the wire device on a steel frame representing a single degree of freedom system and subjected to earthquake time histories with increasing level of excitations.

\section{Pseudoelastic Hysterisis}

Pseudo elastic effect is the property by which the shape memory alloy recovers its initial shape when external load is removed. It occurs in stress induced austenitic to martensitic phase transformation of shape memory alloys. Figure 1(a) shows the experimental stress strain behavior of an austenitic SMA wire stressed uniaxially. On loading $(\mathrm{o}-\mathrm{a}-\mathrm{b}-\mathrm{c})$, the wire, when the stress reaches the transformation level $\sigma_{\mathrm{ms}}$, transformation from austenite to martensite will be induced and this transformation will continue until all the austenite has been transformed to martensite at almost constant stress level (if strain rate is very low). Upon release of stress during unloading, (c-d) martensite unloads elastically down to $\sigma_{\mathrm{as}}$, where it will transform back to austenite (d-e), once again at almost constant stress level (if strain rate is very low). When this transformation is completed, there is final elastic unloading (e-o) of austenite phase. This is called pseudoelastic (superelastic) effect as there is no permanent deformation though the behaviour is nonlinear. However, researchers [12] have observed experimentally that subjecting the austenitic $\mathrm{Ni}$-Ti shape memory alloys to cycles show that some residual martensite is retained in superelastic Ni-Ti shape memory alloys subjected to repeated cyclic loading. This residual martensite progressively increases while increasing the number of cycles and tends to reach a value of $0.4 \%-0.5 \%$ in terms of residual strain after about 50 cycles. This is due to the local stress created in particular at the grain boundaries which locally induces martensite and retains it. Moreover, Liu and Xiang [15] measured the apparent modulus of austenite while loading and unloading and found that the measurement decreased continuously with increasing magnitude of deformation. The slope of $\mathrm{e}^{\prime} \mathrm{o}^{\prime}$ during unloading is $80 \%$ of the slope during loading. In Figure 1, oo' is the residual martensite which is retained at the end of 50 cycles.

\section{SMA Damper Device}

Energy dissipation device was designed making use of the energy dissipation properties of Ni-Ti wires. The wires are austenitic wires which give the energy dissipating as well as the recentering property. The device as shown in Figure 2(a) consists of two concentric pipes which will move mutually. Three studs are attached to inner pipe at angles $120^{\circ}$ apart at two locations. Six studs are attached to outer pipe in the centre equidistant $(100 \mathrm{~mm})$ from the studs attached to the inner pipe. Super-elastic SMA wires having length $100 \mathrm{~mm}$ are attached between these two studs. However, to get a good stroke length of the damper, the length of the wires can be increased. In order to get a good grip on the wires and prevent slipping of the wires during tensile tests, they were fixed to the studs using collets. Thus, the damper consists of 6 wires each of $1.2 \mathrm{~mm}$ diameter connected to studs. The testing of the damper for tension compression sinusoidal loading was done at room temperature of $35^{\circ} \mathrm{C}$. First, the tests were carried out on wires (Figure 1) and then the damper device was tested. It is observed from the figure that the wires can be used effectively for energy dissipation upto a strain of $8 \%$. During testing of the damper one end of the damper is fixed and other end is connected to an actuator. When the damper is loaded, at a time three of the wires are in tension and three are slack. The wires, which will be in tension dissipate earthquake energy and less energy will be transmitted to the structural system. Thus two independent groups of wire loops will act as energy dissipating group. Testing has been carried out on SMA Damper with 3 numbers of $1.2 \mathrm{~mm}$ diameter wires in tension and 3 wires becoming slack at a time. Tests have been carried out by increasing the loading rate from quasistatic conditions $(0.01 \mathrm{~Hz})$ to the loading rate of predominant earthquake frequencies $(0.1 \mathrm{~Hz}-5 \mathrm{~Hz})$. Combined graphs showing one cycle for $3 \mathrm{~Hz}$ loading rate with increasing amplitude are shown in Figure 2(b). It is observed that with change in amplitude for same frequency, the stress at austenite start transformation $\left(\sigma_{\mathrm{as}}\right)$ remains the same while the unloading paths are different at different amplitude of loadings. 


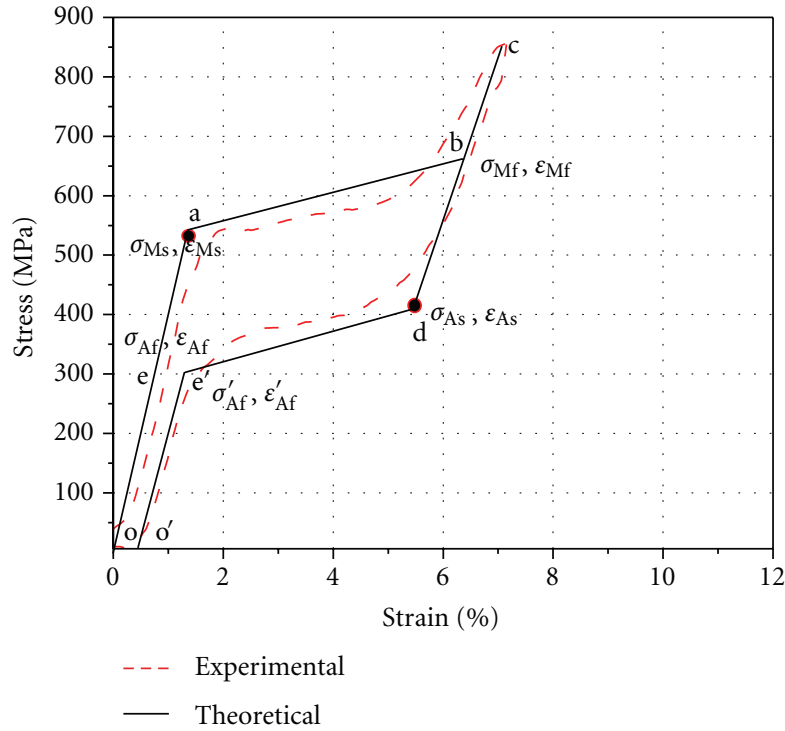

(a)

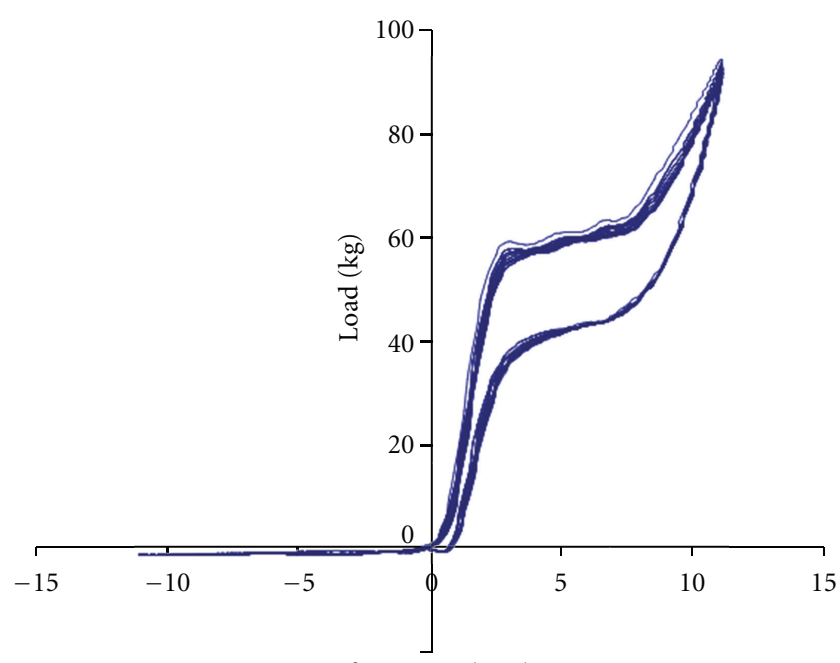

Deformation (mm)

(b)

Figure 1: (a) Pseudoelastic Hysterisis of SMA wire. (b) Force displacement curve for cyclic tensile tests on 1.2 mm dia SMA wire.
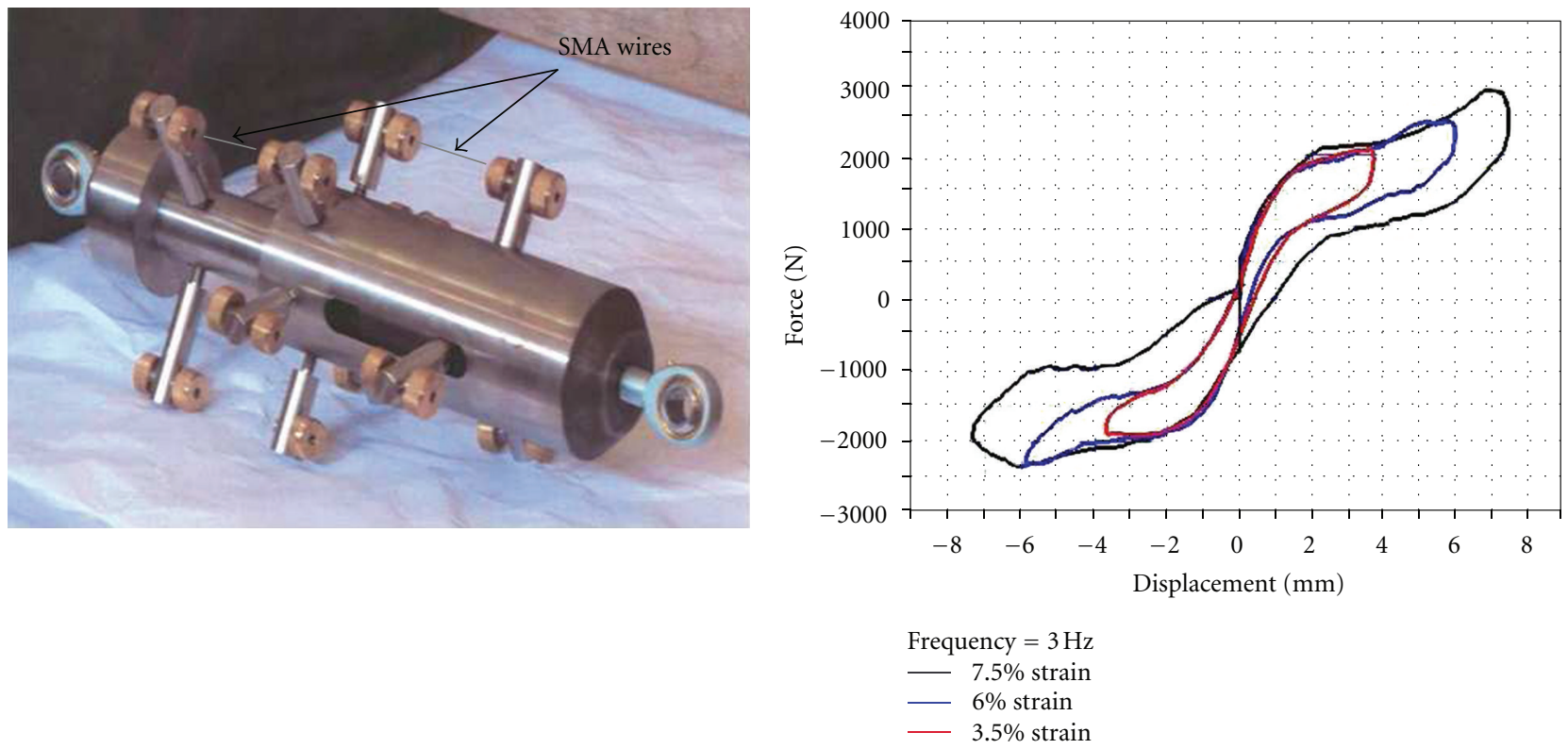

(a)

(b)

FIgURE 2: Shape memory alloy damper device. (a) Schematic. (b) Force displacement relation.

\section{Thermomechanical Model of SMA Damper}

Thermomechanical model based on the original work of Boyd and Lagoudas [8] which is modified [10] to give multilinear stress train relationship is used in the present study. This model is simple and has the ability to capture the cyclic loading effects on SMAs in addition to sub looping behavior resulting from incomplete phase transformation cycles. The uniaxial themo-mechanical behavior of SMAs can be described by constitutive relation

$$
\sigma=E(\xi) \varepsilon-\alpha(\xi) E(\xi)\left(T-T_{s}\right)-E(\xi) \xi \varepsilon_{l},
$$

where $\sigma, \varepsilon, T, T_{\mathrm{s}}$ are the stress, strain, temperature, and start temperature of transformation for a mixture of austenite and martensite material. $E$ and $\alpha$ are the effective Young's Modulus and effective coefficient of thermal expansion attributable 
to transformation. $\varepsilon_{l}$ denotes the maximum residual strain which is material constant and $\xi$ denotes the volume fraction of the martensite phase. Different researchers have proposed different thermomechanical models in which the evolution equation for martensite fraction $\xi$ has exponential and polynomial relation $[7,8]$. The model used in the present study is proposed by Motahari and Ghassemieh [10] in which the evolution equation enforces linear relationship between stress and strain. This model is modified to take into account residual martensite strain of $0.45 \%$ in the stress strain relation path when the pseudo-elastic wire is unloaded.

Considering isothermal process $\left(T=T_{\mathrm{s}}\right)$ for super-elastic behaviour and using (1)

$$
\sigma=E(\xi) \varepsilon-E(\xi) \xi \varepsilon_{l} .
$$

Now considering $E_{\mathrm{A}}$ and $E_{\mathrm{M}}$ Effective Young's moduli of austenite and martensite state, respectively, the subsequent equation is good approximation for polycrystalline SMAs:

$$
E(\xi)=E_{\mathrm{A}}+\left(E_{\mathrm{M}}-E_{\mathrm{A}}\right) \xi,
$$

where function $\xi=f(\varepsilon)$ will be such that

$$
\sigma=E(\xi) \varepsilon-E(\xi) \xi \varepsilon_{l}=a \varepsilon+b,
$$

where $a$ and $b$ can be obtained enforcing the model to pass though finish critical stresses $\backslash$ and strains.

The critical stresses $\left(\sigma_{\mathrm{Ms}}, \sigma_{\mathrm{Mf}}, \sigma_{\mathrm{As}}\right.$, and $\left.\sigma_{\mathrm{Af}}\right)$ and strains $\left(\varepsilon_{\mathrm{Ms}}, \varepsilon_{\mathrm{Mf}}, \varepsilon_{\mathrm{As}}\right.$, and $\left.\varepsilon_{\mathrm{Af}}\right)$ are obtained using the stress strain relationship obtained from wire tests. Sinusoidal cyclic tests were performed on $0.4 \mathrm{~mm}$ diameter and $1.2 \mathrm{~mm}$ diameter superelastic wires for varying displacement amplitudes from $5 \mathrm{~mm}$ to $11 \mathrm{~mm}$ (4\% strain to $9 \%$ strain). The force displacement relationship for $1.2 \mathrm{~mm}$ diameter wire is shown in Figure 1(b). It is observed from the figure that the wires can be used effectively for energy dissipation upto a strain of $8 \%$. With strains greater than $8 \%$, the hysterisis loops narrow and translate upwards, while branches of the curve relevant to the phase transformations harden, thus yielding an increase in stress levels. Similar behaviour was observed by Clark et al. [3]. Tests were also carried out with increasing number of cycles to obtain the fatigue characteristics and it is observed that $1.2 \mathrm{~mm}$ diameter wire is capable of taking 1200 cycles of $7 \mathrm{~mm}$ amplitude (6\% strain) without decrease in the load taken by the wire. Thus, the wires can withstand considerable amount of fatigue loading within a strain range of $2-10 \%$.

Using Figure 1(a), the transformation critical stresses are obtained as $\sigma_{\mathrm{Ms}}=551 \mathrm{MPa}, \sigma_{\mathrm{Mf}}=667 \mathrm{MPa}, \sigma_{\mathrm{As}}=402 \mathrm{MPa}$ and $\sigma_{\mathrm{Af}}=288.1 \mathrm{MPa}$ whereas the critical strains are obtained as $\varepsilon_{\mathrm{Ms}}=0.013, \varepsilon_{\mathrm{Mf}}=0.064, \varepsilon_{\mathrm{As}}=0.054$, and $\varepsilon_{\mathrm{Af}}=0.0068$. The Young's moduli $E_{\mathrm{A}}=42308 \mathrm{MPa}, E_{\mathrm{M}}=28571 \mathrm{MPa}$ and the total phase strain value, $\varepsilon_{l}=0.04$, is also obtained from the uniaxial tests in wires. The maximum value of residual matrensite strain, $\varepsilon_{\text {ir,max }}$, is obtained from tests on wires as 0.0045. Modulus of elasticity of Austenite Ni-Ti was measured for unloading and reloading by Liu and Xiang and it was observed that the modulus of elasticity for unloading is 15-20\% lesser than that for loading [15]. This occurs due to contribution of a second deformation mechanism operating during the apparent elastic deformation of a specimen. This second deformation mechanism may be either the stressinduced martensitic transformation or martensite reorientation, depending on the starting structure. Thus, considering the modulus of elasticity of unloading as 35055, it is observed that the values of $\sigma_{\mathrm{Af}}^{\prime}$ and $\varepsilon_{\mathrm{Af}}^{\prime}$ are obtained as $303.44 \mathrm{MPa}$ and 0.0132 , respectively.

The transformation temperatures for the SMA considered in present study are $M_{\mathrm{f}}=-80^{\circ} \mathrm{C}, M_{\mathrm{s}}=-60^{\circ} \mathrm{C}, A_{\mathrm{s}}=$ $-25^{\circ} \mathrm{C}$, and $A_{\mathrm{f}}=-8^{\circ} \mathrm{C}$. The tests on SMA wires have been carried out at room temperature hence $T_{\mathrm{s}}=35^{\circ} \mathrm{C}$. Using the phase diagram (Figure 3(a)) and the pseudoelastic multilinear loading path (Figure 3(b)), the transformation constants $C_{\mathrm{A}}$ and $C_{\mathrm{M}}$ are obtained as $6.7 \mathrm{Mpa}$ and $5.8 \mathrm{MPa}$, respectively. These values are in agreement with those obtained by Boyd and Lagoudas [8] for pseudo-elastic NiTi alloys. The stress strain relations on the paths in Figure 3(b) are as follows.

Elastic fully austenitic (loading), Path O-A and E-O:

$$
\sigma=E_{\mathrm{A}} \varepsilon
$$

Forward Transformation (loading), Path A-B:

$$
\sigma=\sigma_{\mathrm{Ms}}+\frac{\sigma_{\mathrm{Mf}}-\sigma_{\mathrm{Ms}}}{\varepsilon_{\mathrm{Mf}}-\varepsilon_{\mathrm{Ms}}}\left(\varepsilon-\varepsilon_{\mathrm{Ms}}\right) .
$$

Elastic fully martensite (unloading), Path B-C and C-D:

$$
\sigma=\sigma_{\mathrm{Mf}}+E_{\mathrm{M}}\left(\varepsilon-\varepsilon_{\mathrm{Mf}}\right)
$$

Reverse Transformation (unloading), Path D-E':

$$
\sigma=\sigma_{\mathrm{As}}+\frac{\sigma_{\mathrm{Af}}^{\prime}-\sigma_{\mathrm{As}}}{\varepsilon_{\mathrm{Af}}^{\prime}-\varepsilon_{\mathrm{As}}}\left(\varepsilon-\varepsilon_{\mathrm{As}}\right) .
$$

Unloading in elastic Austenitic with residual martensite strain for $\varepsilon<\varepsilon_{\text {Af }}^{\prime}$ (i.e., 0.0132), Path $\mathrm{E}^{\prime} \mathrm{O}^{\prime \prime}$ :

$$
\sigma=\frac{\sigma_{\mathrm{Af}}^{\prime}}{\varepsilon_{\mathrm{Af}}^{\prime}-\varepsilon_{\mathrm{ir}}}\left(\varepsilon-\varepsilon_{\mathrm{ir}}\right),
$$

$\sigma_{\mathrm{Af}}^{\prime}$ and $\varepsilon_{\mathrm{Af}}^{\prime}$ are the stress and the strain corresponding to austenite finish states taking into account the residual strain, $\varepsilon_{\text {ir }}$. The maximum value of this strain is limited to $\varepsilon_{\text {ir max }}$ (i.e., $0.45 \%$ ) for complete martensite transformation. Lexcellent and Bourbon [11] stated that for cycles with incomplete martensite transformations residual stress will depend on the residual martensite fraction $Z_{\mathrm{ir}}$. The maximum residual strain is proportional to maximum residual martensite fraction by the relation

$$
\varepsilon_{\text {ir max }}=\varepsilon_{l} Z_{\text {ir }},
$$

where $\varepsilon_{l}=0.04$ is the total phase strain. Thus for the incomplete phase transformation strain say $\gamma$ the residual martensite strain will be given by relation

$$
\varepsilon_{\text {ir }}=\frac{\varepsilon_{\text {ir } \max }}{\varepsilon_{l}} \gamma
$$

If unloading occurs before the completion of forward transformation or reloading begins before the completion 


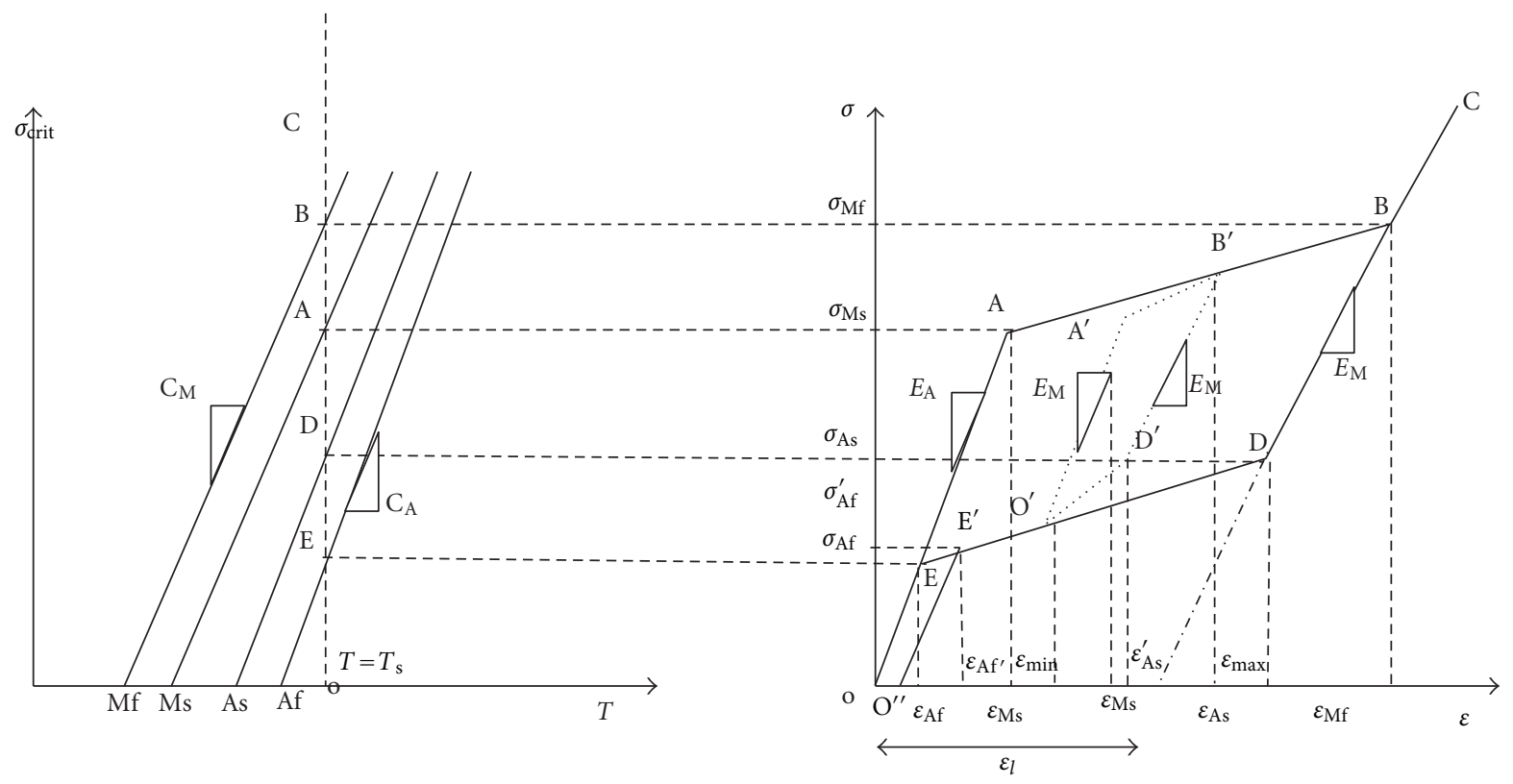

(a)

(b)

Figure 3: (a) Phase diagram for pseudoelasticity. (b) Pseudoelasticity loop and subloop.

of reverse transformation, then the elastic stiffness would be different from both austenite and martensite phases. If $L_{\mathrm{m}}$ and $L_{\mathrm{a}}$ are the compliances of mixture constituents and they have linear relationship with strain [1]:

$$
L_{\mathrm{m}}=x L_{\mathrm{M}}+(1-x) L_{\mathrm{A}},
$$

in which $x$ is $\left(\varepsilon_{\max }-\varepsilon_{\mathrm{Ms}}\right) /\left(\varepsilon_{\mathrm{Mf}}-\varepsilon_{\mathrm{Ms}}\right)$ for unloading and $x$ is $\left(\varepsilon_{\min }-\varepsilon_{\mathrm{Af}}\right) /\left(\varepsilon_{\mathrm{As}}-\varepsilon_{\mathrm{Af}}\right)$ for reloading.

Where $\varepsilon_{\max }$ and $\varepsilon_{\min }$ are maximum and minimum strains before unloading or reloading as shown in Figure 3(b), the elastic stiffness would become:

$$
E_{\mathrm{m}}=\frac{E_{\mathrm{M}} E_{\mathrm{A}}}{x\left(E_{\mathrm{A}}-E_{\mathrm{M}}\right)+E_{\mathrm{M}}} .
$$

The new values for critical austenite strain will be obtained as:

$$
\varepsilon_{\mathrm{As}}^{\prime}=\varepsilon_{\max }+\frac{\sigma_{\mathrm{As}}-\sigma_{\max }}{E_{\mathrm{m}}} .
$$

Similarly, new value of critical martensite strain, $\varepsilon_{\mathrm{Ms}}^{\prime}$ is obtained by substituting $\varepsilon_{\max }, \sigma_{\max }$ and $\sigma_{\mathrm{As}}$ by $\varepsilon_{\min }, \sigma_{\min }$ and $\sigma_{\mathrm{Ms}}$, respectively. Where $\sigma_{\max }$ and $\sigma_{\min }$ are stresses corresponding to strains $\varepsilon_{\max }$ and $\varepsilon_{\min }$, the stress strain relations on the subloop paths shown in Figure 3(b) are as follows:

Path $\mathrm{O}^{\prime} \mathrm{A}^{\prime}$ :

$$
\sigma=\sigma_{\min }+E_{\mathrm{m}}\left(\varepsilon-\varepsilon_{\min }\right),
$$

Path $A^{\prime} B^{\prime}$

$$
\sigma=\sigma_{\mathrm{Ms}}+\frac{\sigma_{\mathrm{Mf}}-\sigma_{\mathrm{Ms}}}{\varepsilon_{\mathrm{Mf}}-\varepsilon_{\mathrm{Ms}}^{\prime}}\left(\varepsilon-\varepsilon_{\mathrm{Ms}}^{\prime}\right)
$$

Path $\mathrm{B}^{\prime} \mathrm{D}^{\prime}$

$$
\sigma=\sigma_{\max }+E_{\mathrm{m}}\left(\varepsilon-\varepsilon_{\max }\right),
$$

Path $\mathrm{D}^{\prime} \mathrm{O}^{\prime}$

$$
\sigma=\sigma_{\mathrm{As}}+\frac{\sigma_{\mathrm{Af}}-\sigma_{\mathrm{As}}}{\varepsilon_{\mathrm{Af}}-\varepsilon_{\mathrm{As}}^{\prime}}\left(\varepsilon-\varepsilon_{\mathrm{As}}^{\prime}\right) .
$$

For the complete stress strain relationship of the SMA damper device subjected to cyclic loading, it is essential to define the stress strain path when the damper will undergo compression load. During compressive load, another set of three wires go in tension according to the design of the damper. Thus, when the load becomes negative during unloading, that is, Path O"F (see Figure 4), stress-strain relation ship, will be equivalent to that of unloading in elastic austenitic with reduced modulus of Elasticity, equivalent to $80 \%$ of initial modulus $E_{\mathrm{A}}$ and with residual martensite strain (Path $\left.\mathrm{E}^{\prime} \mathrm{O}^{\prime \prime}\right)$.

\section{Path O"F}

$$
\sigma=\frac{\sigma_{\mathrm{Af}}^{\prime}}{\varepsilon_{\mathrm{Af}}^{\prime}-\varepsilon_{\mathrm{ir}}}\left(\varepsilon-\varepsilon_{\mathrm{ir}}\right),
$$

where $\sigma_{\mathrm{Af}}^{\prime}$ and $\varepsilon_{\mathrm{Af}}^{\prime}$ are the stress and the strain corresponding to austenite finish states taking into account the residual strain.

During further unloading Path FG

$$
\sigma=E_{\mathrm{A}} \varepsilon,
$$

where $E_{\mathrm{A}}$ is the initial elastic modulus of austenite. For further unloading (Path GH) stress strain characteristics will be similar to Path $\mathrm{AB}$. 


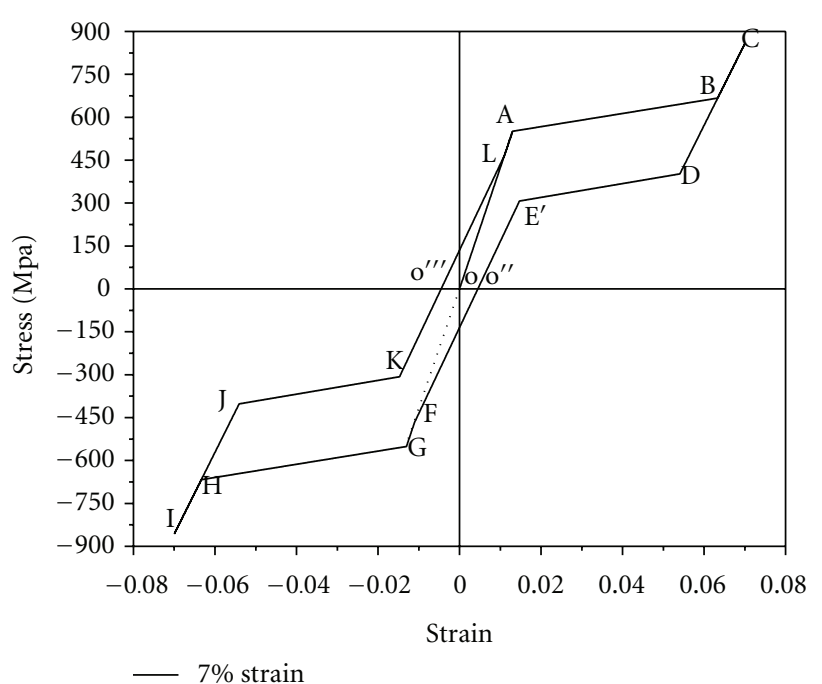

FIGURE 4: Stress strain relationship of damper.

Using (5)-(20) and the critical stress and strains obtained from the wires characteristics, the load deflection characteristics of the damper device is obtained. This theoretical load deflection characteristic is compared with that obtained by experiments. Figure 5 shows the comparison for $3.75 \%$ and $6 \%$ strain. The hysterisis loop of the experiments and theory are in good agreement. The analytical model shows the residual deformation in the hysterisis loop when the load is less than austenite finish state. This model is an improvement of the models proposed in literature $[9,10]$ where the force displacement characteristics shows same linear path for loading and unloading when the load is less than Austenite finish state. The force displacement characteristics of the analytical model thus well predict the energy dissipated in SMA wires compared to the previous models mentioned in literature. The cyclic stress strain relationship for varying peak strain (2-7\%) using the analytical model is shown in Figure 6. The shaft friction between the two cylinders of the damper device is negligible due to lubrication between the two surfaces using oil lubricants. It is observed that the theoretical load deflection characteristic is higher than experimental in some parts while it is lower in some other parts. However considering the overall area of energy dissipation the theoretical and experimental results are in good agreement.

\section{SMA Analytical Models}

In this paper three SMA models from literature are investigated and response of a steel framed structure with these models is compared with that of the proposed SMA model. The first model considered is a simplified model which is experimental based as given by Thomson et al. [2] in which the hysteretic properties are predefined and are independent of thermomechanical properties of SMA. The second model considered is the multilinear thermomechanical model given by Boyd and Lagoudas [8] and modified by Motahari and Ghassemieh [10]. This model has an ability to capture the

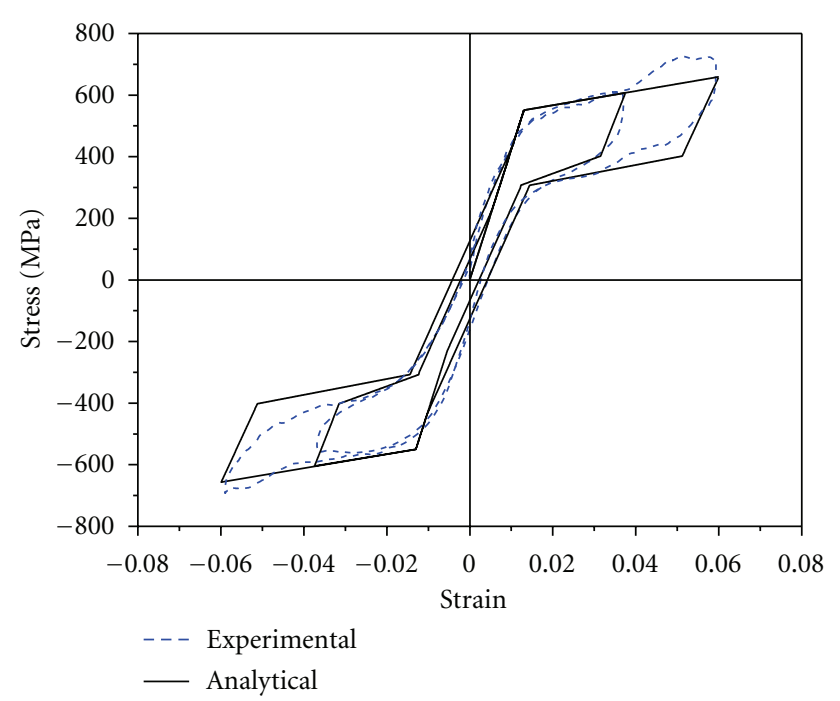

FIGURE 5: Comparison of experimental and analytical stress strain relation ship.

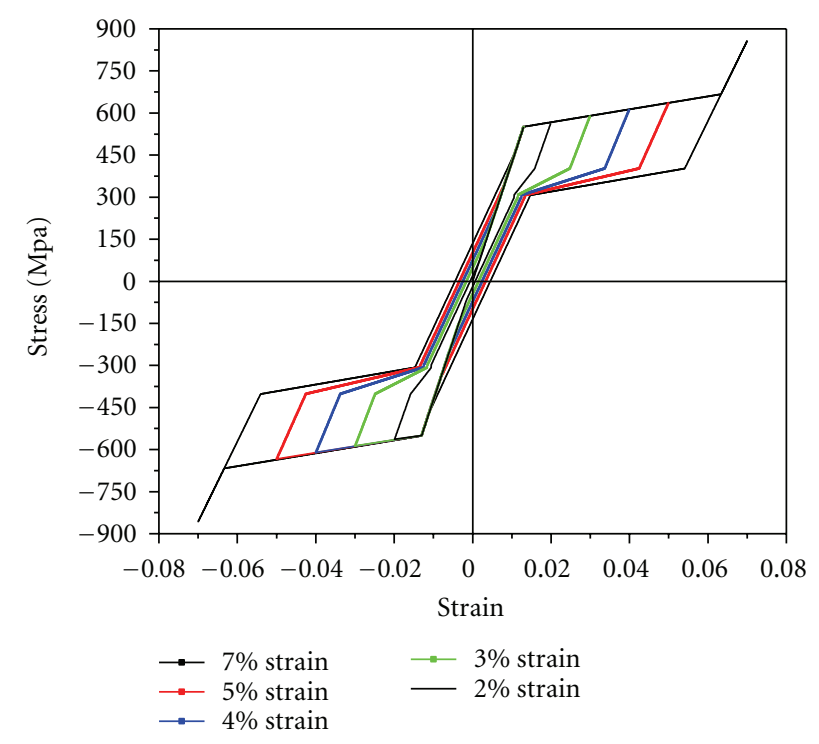

FIGURE 6: Cyclic stress strain relationship for varying peak strain.

cyclic loading effects on SMAs in addition to the sub looping behaviour resulting from incomplete phase transformations. The third model considered is mentioned in Parulekar et al. [14]. This model is the modified version of the model brought out by Motahari and Ghassemieh which further takes into account the effect of residual martensite strain accumulated during cyclic loading.

\section{Experiment and Analysis of Steel Structure}

The six-storey steel structural model shown in Figure 7(a) tested on shake table is considered for the analysis. Mass of 6.0 tons representing the mass of a tank is placed on the 4th storey in form of plates and the total mass of the structure is 6.9 tons. 


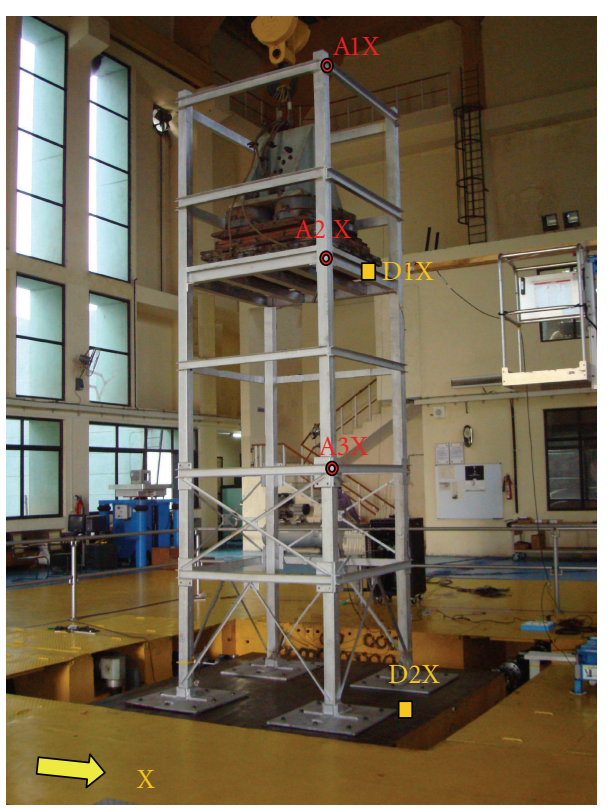

(a)

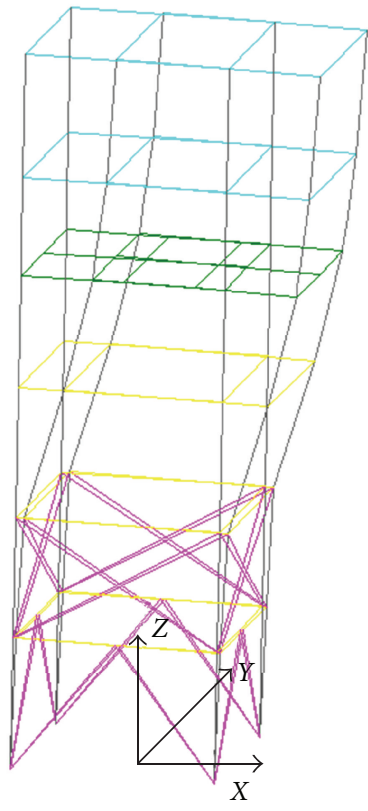

(b)

FIGURE 7: Model of the steel structure. (a) Test model. (b) FE model showing mode shape (Frequency = 3.1 Hz).

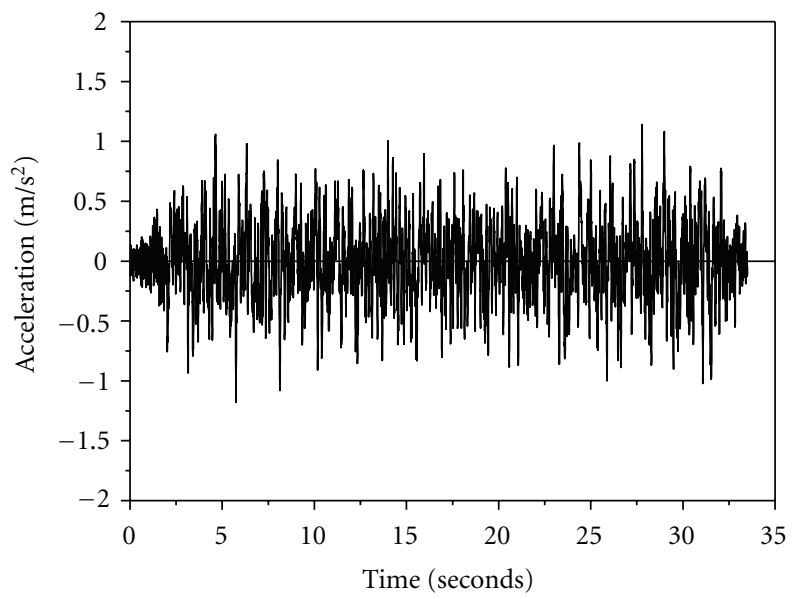

(a)

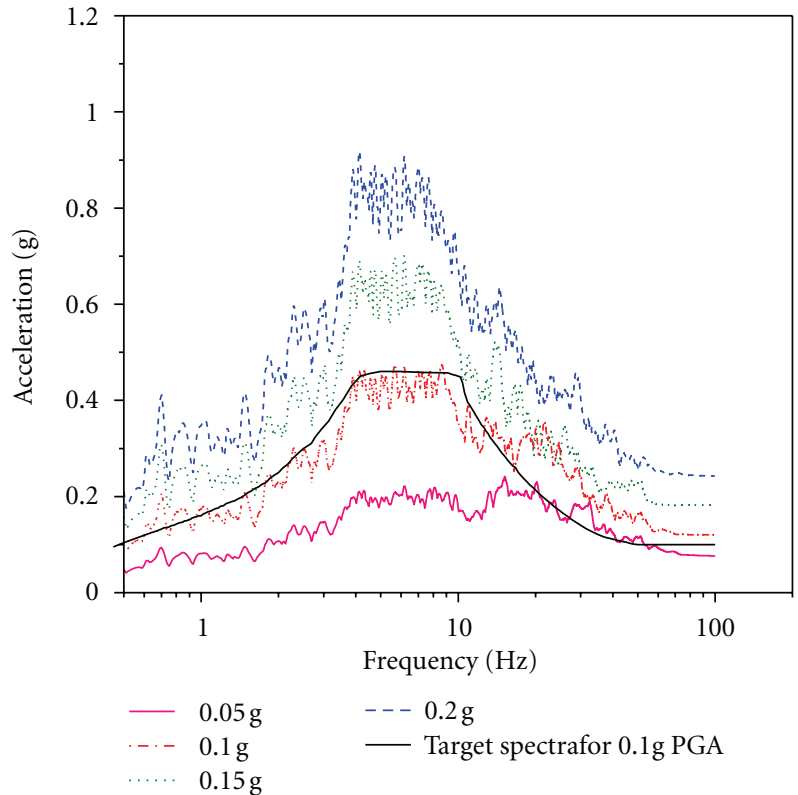

(b)

Figure 8: (a) Spectrum compatible time history. (b) Response spectrum for 2\% damping.

Sine sweep tests are carried out on the structure. Transfer function is obtained and the resonance frequency is $3.05 \mathrm{~Hz}$ and the damping is obtained as $2 \%$. The model is then subjected to spectrum compatible time histories shown in Figure 8(a) with peak acceleration increasing from $0.05 \mathrm{~g}$ to $0.2 \mathrm{~g}$. The response spectra for the test time histories and target response spectra are shown in Figure 8(b). The spectra are plotted for damping of $2 \%$ which is obtained from the experiments. Time history analysis is carried out for the steel structure for the spectrum compatible time history of $0.05 \mathrm{~g}$ to $0.2 \mathrm{~g}$ PGA with increment of $0.05 \mathrm{~g}$. The analysis results are compared with the test results. The first fundamental frequency of the structure is $3.1 \mathrm{~Hz}$ with $96 \%$ mass participation in the first mode (Figure 7(b)). Thus, the structure can be idealized as a single degree of freedom system. The comparison of test and analysis displacement time histories at 


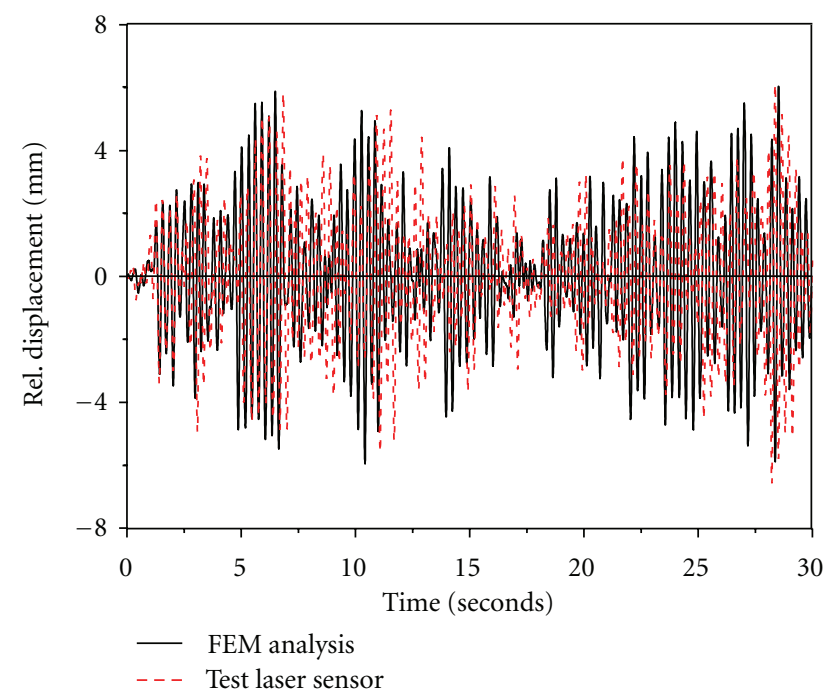

FIGURE 9: Comparison of test and analysis displacement time histories at mass level for $0.1 \mathrm{~g}$ PGA.

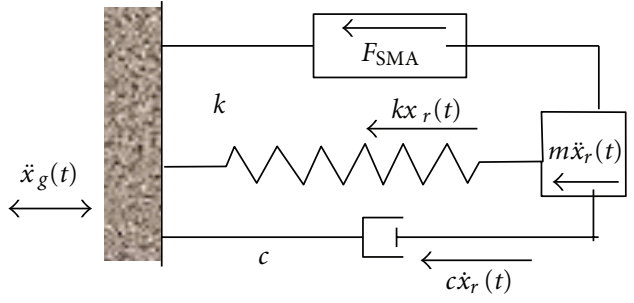

FIgURE 10: SDOF system with SMA damper.

the mass level of the frame is shown in Figure 9 for $0.1 \mathrm{~g}$ PGA. It is observed from the figure that the analysis and test response are in good agreement with each other. The maximum difference in peak response in test and analysis is about $10 \%$. The displacements and accelerations obtained at various floors of the structure in linear analysis at $0.1 \mathrm{~g}$ peak base acceleration are obtained from the analysis of single degree of freedom system by multiplying the displacement and acceleration obtained at the mass with the spatial representation vector $\{\phi\}$.

\section{Nonlinear Analysis of Frame with SMA Models}

The SMA damper consisting of 4 wires of $1.2 \mathrm{~mm}$ dia acting simultaneously in tension is to be placed on either side of the steel frame. Thus, at a time 8 wires ( 4 on either side of the frame) will be in tension with its force and displacement required for martensitic transformation as $4950 \mathrm{~N}$ and $1.3 \mathrm{~mm}$, respectively. The structure can be idealized as a single degree of freedom system connected with SMA damper as shown in Figure 10. The equation of motion for such a case is written as:

$$
m \ddot{x}(t)+k x(t)+c \dot{x}(t)+F_{\mathrm{SMA}}(t)=-m \ddot{x}_{g}(t),
$$

where $m$ is the mass attached to the structure, $c$ is the damping coefficient, $k$ is the stiffness of the structure, $x(t), \dot{x}(t)$, $\ddot{x}(t)$ are the displacement velocity and acceleration of the structure at the lumped mass and $\ddot{x}_{g}(t)$ is the base acceleration. $F_{\mathrm{SMA}}(t)$ is the force exerted on the structure by SMA damper. Stress strain relations of SMA damper can be used to describe the $F_{\mathrm{SMA}}$ when the damper has complete and incomplete phase transformations. Nonlinear time history (TH) analysis is performed for the structure implemented with damper considering four different models. Analysis is performed for the spectrum compatible earthquake time history shown in Figure 8 with peak acceleration from $0.05 \mathrm{~g}$ to $0.2 \mathrm{~g}$.

\section{Results and Discussion}

The comparison of the force displacement relationship of the damper considering all the four models for $0.05 \mathrm{~g}$ and $0.15 \mathrm{~g}$ is shown in Figures 11 and 12, respectively. The force deformation characteristics for thermomechanical model show slight increase in maximum deflection than the simplified model for $0.05 \mathrm{~g}$ and $0.15 \mathrm{~g}$ peak excitation. This is because the thermomechanical model showed more realistic unloading path than the simplified model. Moreover, there was reduction in level of force during unloading thus the energy dissipated was less than the simplified model. This resulted 


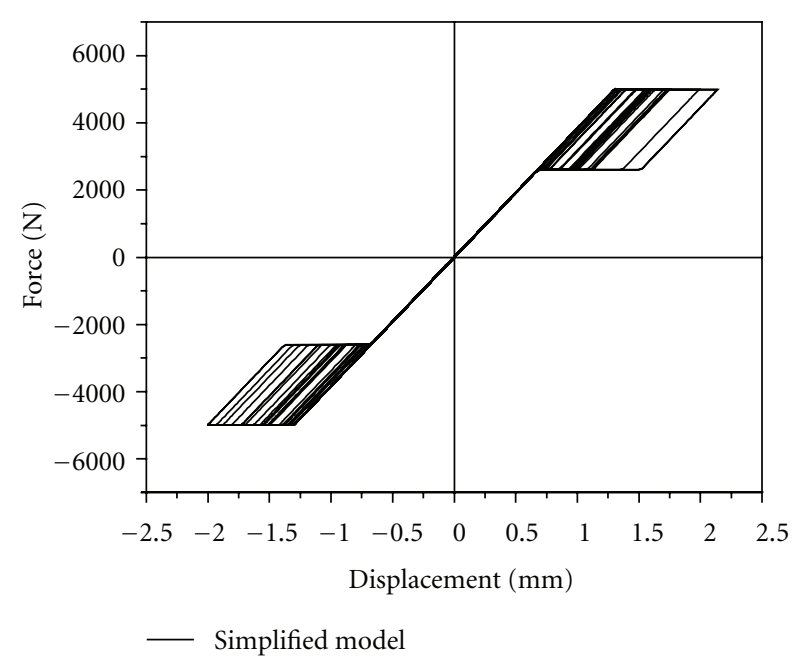

(a)

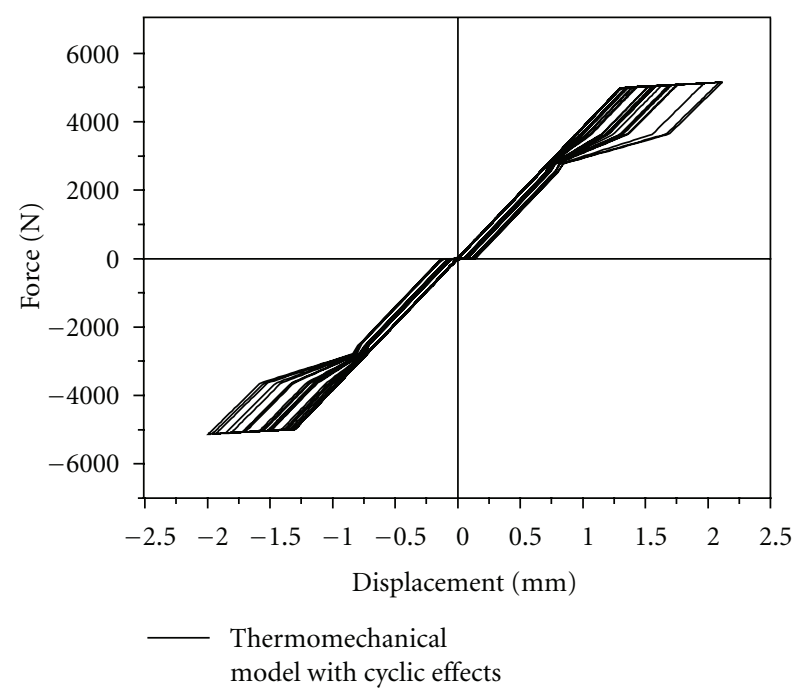

(c)

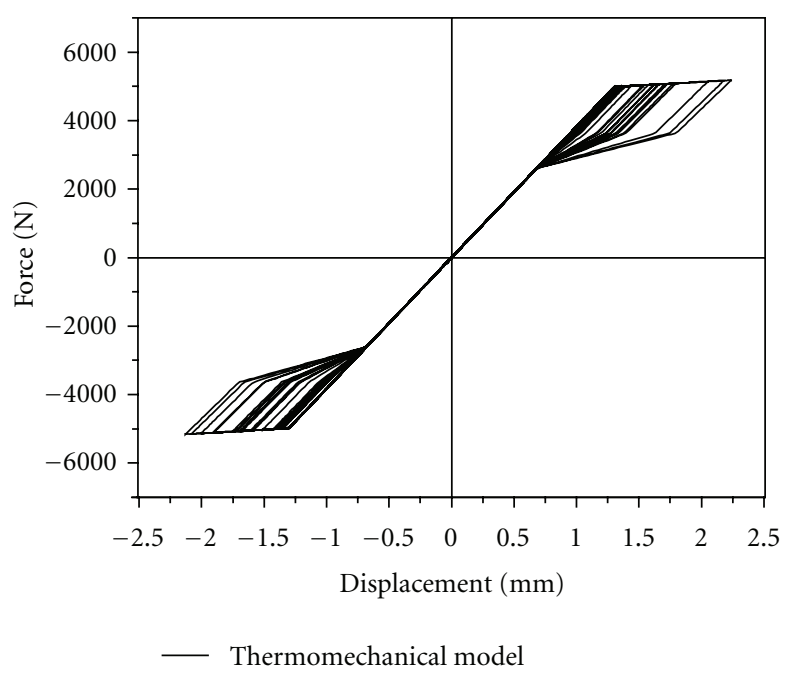

(b)

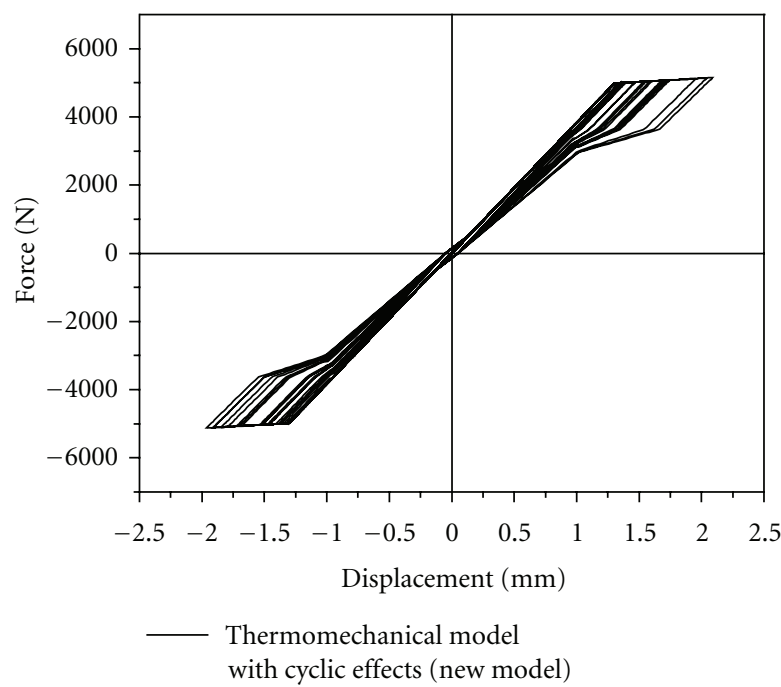

(d)

FIGURE 11: Comparison of force displacement characteristics of SMA damper models for $0.05 \mathrm{~g}$ peak base excitation.

in slight increase in the maximum displacement. The force deflection characteristics of Thermomechanical model with cyclic effects show slightly lesser maximum displacement than the simplified model and the thermomechanical model. The energy dissipated in thermomechanical model with cyclic effects is higher due to the residual strain accumulation which reduces the maximum displacement. The reduction in the response of the structure with SMA damper for increasing base excitation considering the different SMA models is shown in Figure 13.

Figure 13 shows that the response reduction of thermomechanical model with cyclic effects is higher than that of simplified model and the thermomechanical model. The displacement response of simplified model is quite close to the thermomechanical model and average difference in displacement response between the two models is about $4 \%$. It is also observed from the figure that the response reduction of the structure with damper decreases with increase in peak base excitation level. The damping due to hysterisis deformation of SMA is proportional to ratio of hysterisis energy to strain energy. Due to increase in strain energy of structure with increase in peak base excitation the damping decreases with excitation level and thus the response reduction decreases. It is also observed that the newly proposed model with residual martensite strain is more effective in capturing the energy dissipation of the SMA damper device. For higher excitation, if the damper undergoes nonlinear displacement greater than $6.4 \mathrm{~mm}$ (i.e., higher than complete martensite transformation strain, $\varepsilon_{\mathrm{Af}}$ of $6.4 \%$ ), the wires undergo martensitic hardening of the SMA. As the PGA further increases, the elastic response with modulus $E_{\mathrm{M}}$ of pure martensite follows. Figure 12 shows that at $0.15 \mathrm{~g}$ peak base excitation, the peak response displacement of structure with damper is $6.8 \mathrm{~mm}$ and thus the wires undergo maximum strain of $6.8 \%$. It is observed experimentally that the maximum strain taken by SMA wires is about $10 \%$ and hence the damper designed 


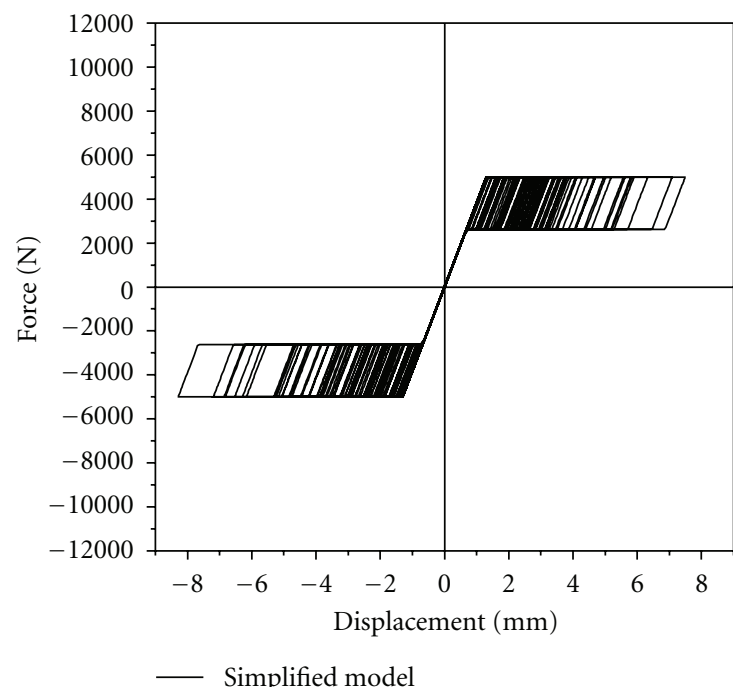

(a)

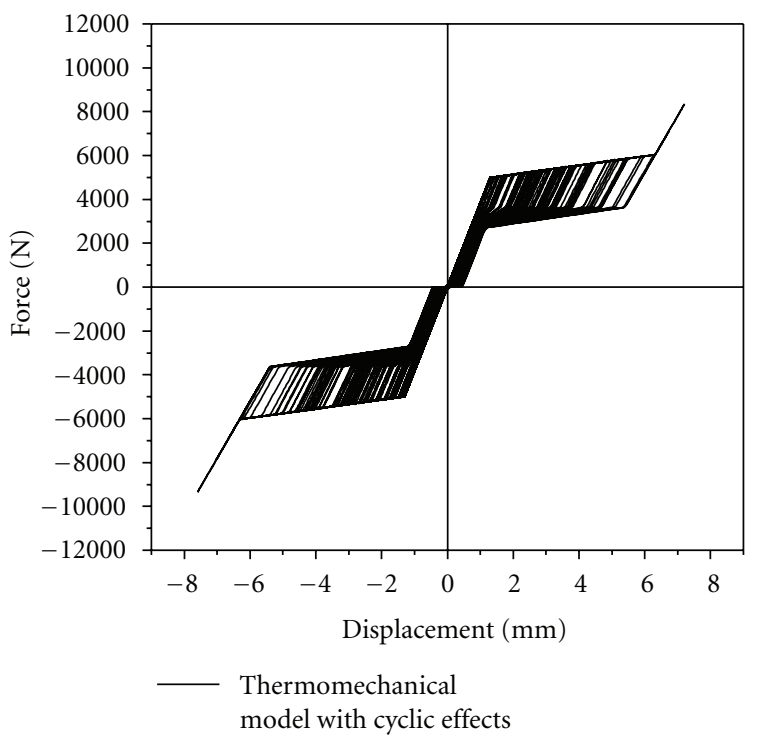

(c)

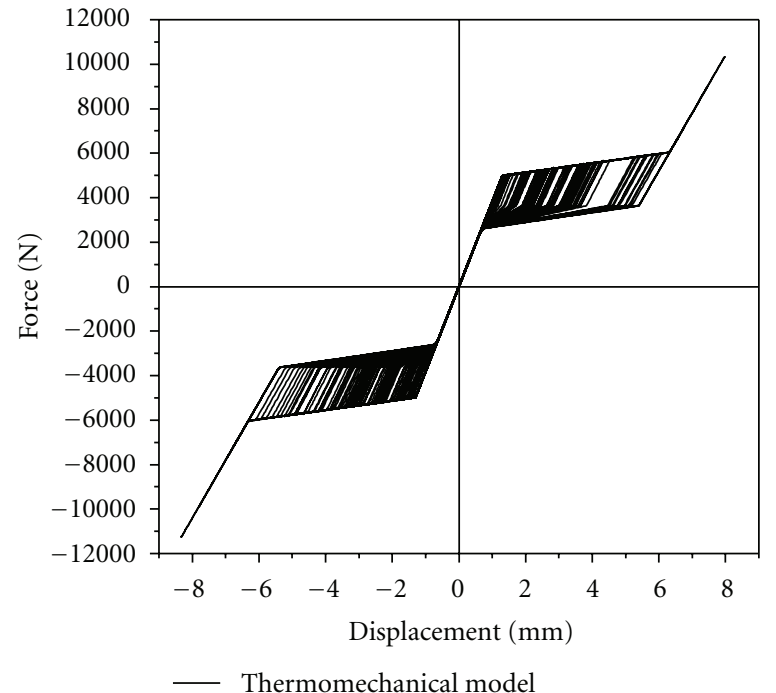

(b)

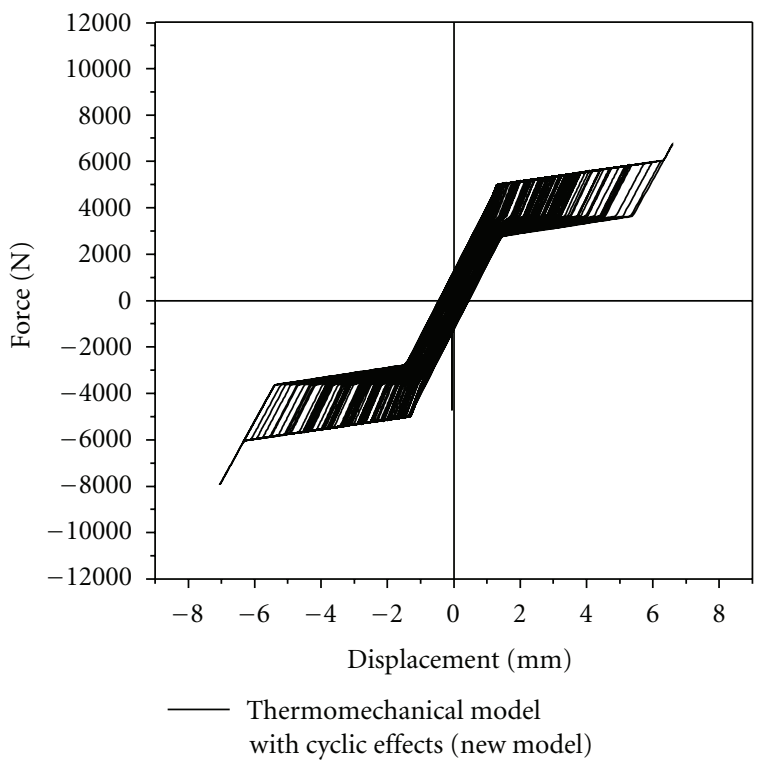

(d)

FIGURE 12: Comparison of force displacement characteristics of SMA damper models for $0.15 \mathrm{~g}$ peak base excitation.

can be used for peak base excitation of $0.2 \mathrm{~g}$. However, for higher excitation damper should be designed for better stroke by increasing the length of the wires used. It is also observed from Figure 13 that the reduction in displacement response for $0.05 \mathrm{~g}, 0.1 \mathrm{~g}, 0.15 \mathrm{~g}$, and $0.2 \mathrm{~g}$ is $41 \%, 43 \%, 31 \%$, and 22\%, respectively, for the new SMA model considering cyclic effects. For higher excitation (greater than $0.15 \mathrm{~g}$ ), the damper undergoes martensite hardening and the effectiveness of damper decreases. Moreover, for higher excitation the increase is strain energy effect also decreases the damping given by the SMA damper. Hence, it is essential that the number of wires and the length of the wires should be increased to maintain the effectiveness of damper subjected to higher excitation.

\section{Conclusions}

The mechanical behavior of superelastic shape memory alloys suits the optimal requirements of a seismic control device. A thermomechanical model of pseudoelastic shape memory alloy damper device is developed. This model includes the cyclic effects of SMAs considering accumulation of martensite strain. This damper device is implemented on a steel-framed structure and the structural response using three simplified models from literature is compared with that obtained using proposed model. It is observed that the force deflection characteristics of the thermomechanical model with cyclic effects show slightly lesser maximum displacement than the simplified model and the thermomechanical 


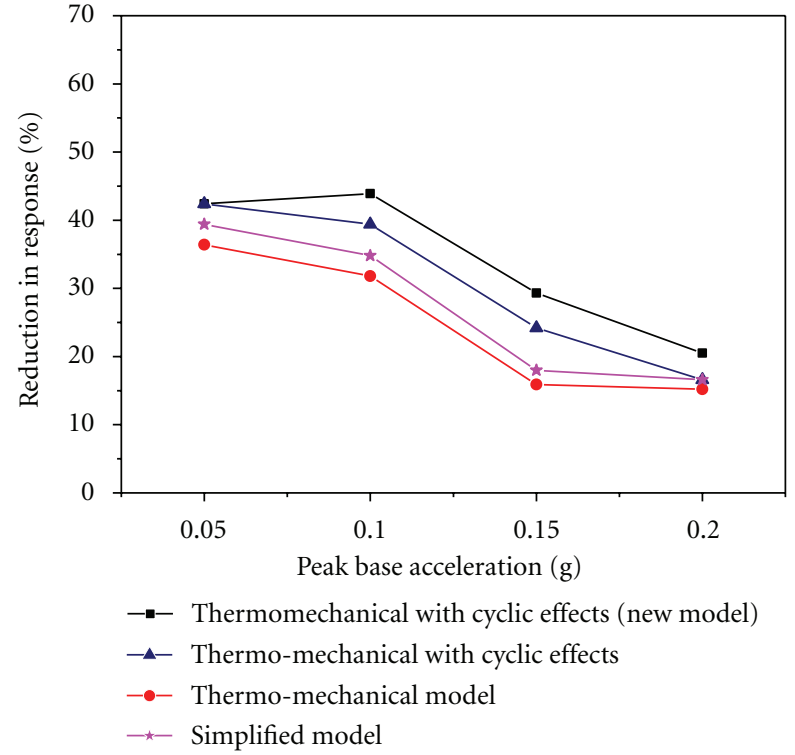

FIGURE 13: Reduction in response for different SMA damper models with peak base excitation.

model. It is observed that the proposed model is more effective in capturing the real characteristics of SMA than the other models. For higher excitation, the effectiveness of SMA damper decreases due to martensitic hardening of SMAs for higher strains. It is observed that the average reduction in response of the steel structure with SMA damper device is about $35 \%$.

\section{References}

[1] E. J. Graesser and F. A. Cozzarelli, "Shape-memory alloys as new materials for aseismic isolation," Journal of Engineering Mechanics, vol. 117, no. 11, pp. 2590-2608, 1991.

[2] P. Thomson, G. J. Balas, and P. H. Leo, "The use of shape memory alloys for passive structural damping," Smart Materials and Structures, vol. 4, no. 1, pp. 36-41, 1995.

[3] P. W. Clark, I. D. Aiken, J. M. Kelly, M. Higashino, and R. C. Krumme, "Experimental and analytical studies of shapememory alloy dampers for structural control," in Proceedings of SPIE - The International Society for Optical Engineering, vol. 2445, pp. 241-251, 1995.

[4] M. Dolce, D. Cardone, and R. Marnetto, "Implementation and testing of passive control devices based on shape memory alloys," Earthquake Engineering and Structural Dynamics, vol. 29, no. 7, pp. 945-968, 2000.

[5] M. Dolce, D. Cardone, F. Ponzo, and C. Valente, "Shaking table tests on reinforced concrete frames without and with passive control systems," Earthquake Engineering and Structural Dynamics, vol. 34, no. 14, pp. 1687-1717, 2005.

[6] K. Tanaka, "Thermo-mechanical sketch of shape memory effect: one dimensional tensile behaviour," Res Mechanica, vol. 18, no. 3, pp. 251-263, 1986.

[7] C. Liang and C. A. Rogers, "A multi-dimensional constitutive model for shape memory alloys," Journal of Engineering Mathematics, vol. 26, no. 3, pp. 429-443, 1992.

[8] J. G. Boyd and D. C. Lagoudas, "A thermodynamical constitutive model for shape memory materials. Part I. The monolithic shape memory alloy," International Journal of Plasticity, vol. 12, no. 6, pp. 805-842, 1996.

[9] M. M. Khan, D. C. Lagoudas, J. J. Mayes, and B. K. Henderson, "Pseudoelastic SMA spring elements for passive vibration isolation: part I-modeling," Journal of Intelligent Material Systems and Structures, vol. 15, no. 6, pp. 415-441, 2004.

[10] S. A. Motahari and M. Ghassemieh, "Multilinear one-dimensional shape memory material model for use in structural engineering applications," Engineering Structures, vol. 29, no. 6, pp. 904-913, 2007.

[11] C. Lexcellent and G. Bourbon, "Thermodynamical model of cyclic behaviour of $\mathrm{Ti}-\mathrm{Ni}$ and $\mathrm{Cu}-\mathrm{Zn}-\mathrm{Al}$ shape memory alloys under isothermal undulated tensile tests," Mechanics of Materials, vol. 24, no. 1, pp. 59-73, 1996.

[12] S. Miyazaki, T. Imai, Y. Igo, and K. Otsuka, "Effect of cyclic deformation on the pseudoelastic characteristics of Ti-Ni alloys," Metallurgical Transactions A, vol. 17, no. 1, pp. 115-120, 1986.

[13] B. Andrawes and R. DesRoches, "Sensitivity of seismic applications to different shape memory alloy models," Journal of Engineering Mechanics, vol. 134, no. 2, pp. 173-183, 2008.

[14] Y. M. Parulekar, G. R. Reddy, K. K. Vaze et al., "Seismic response attenuation using of structures using shape memory alloy dampers," Journal of Structural Control and Health Monitoring, 2011.

[15] Y. Liu and H. Xiang, "Apparent modulus of elasticity of nearequiatomic NiTi," Journal of Alloys and Compounds, vol. 270, no. 1-2, pp. 154-159, 1998. 

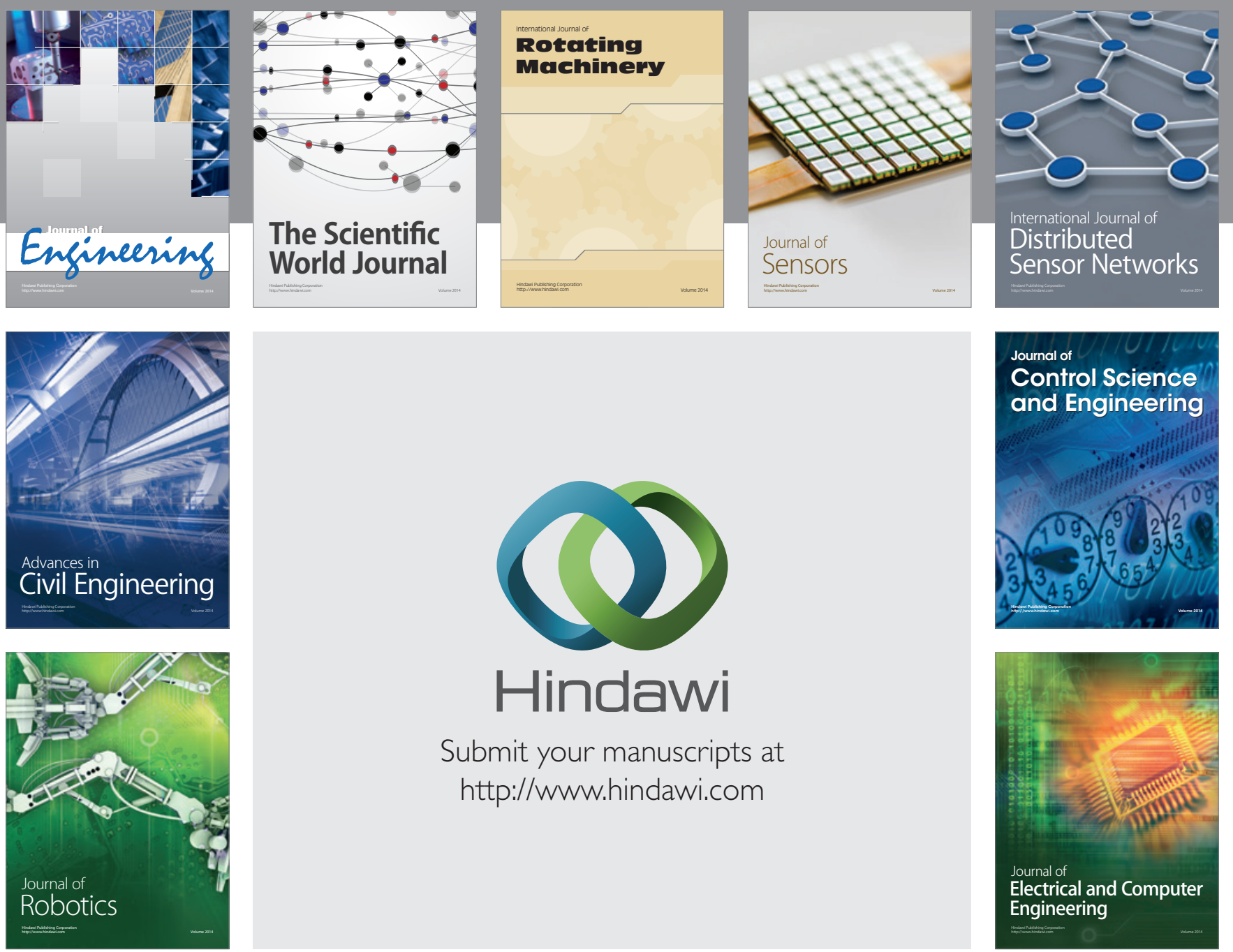

Submit your manuscripts at

http://www.hindawi.com
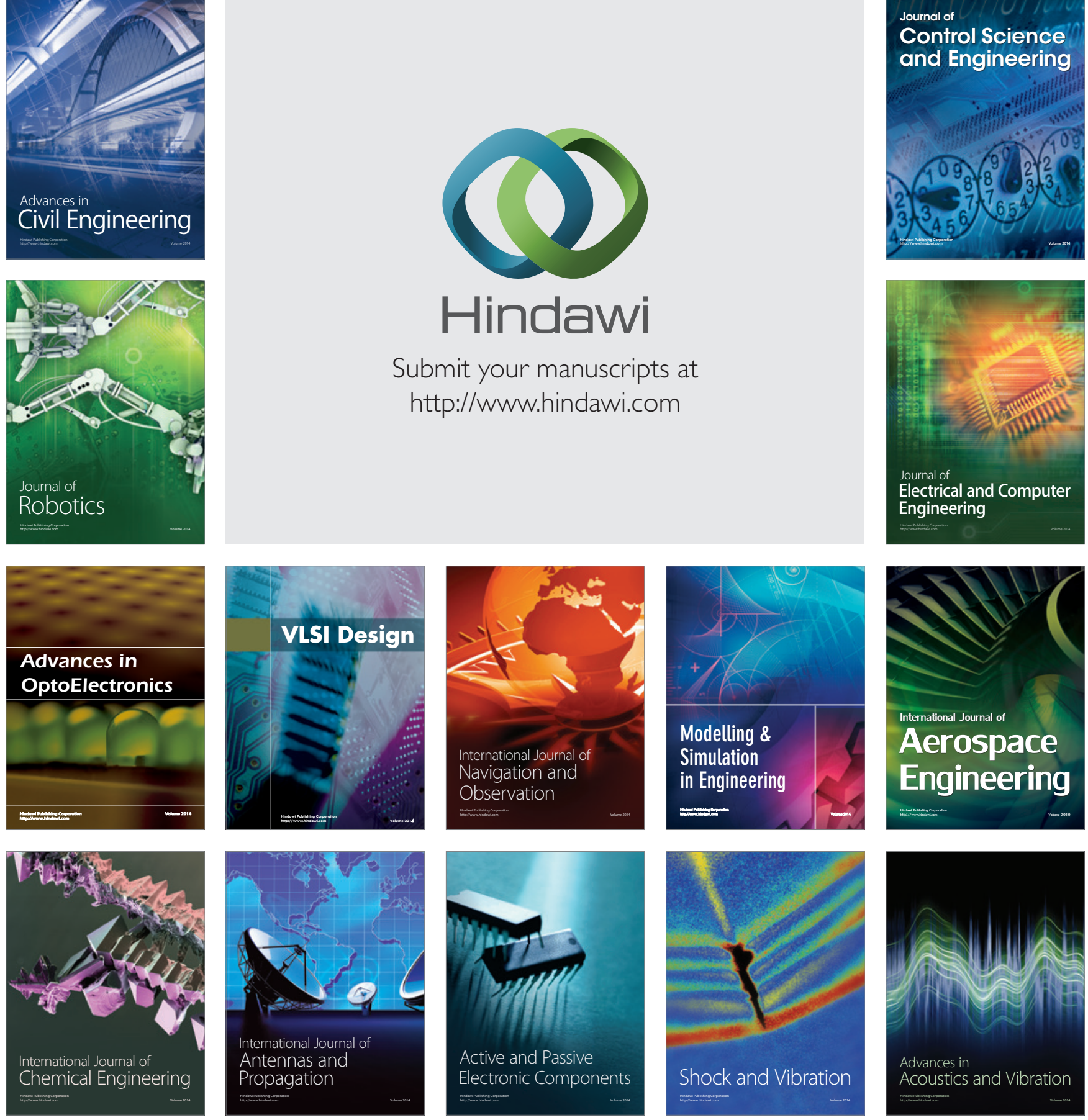